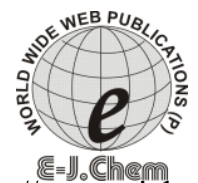

http://www.ejchem.net

ISSN: 0973-4945; CODEN ECJHAO

E-Journal of Chemistry

2012, 9(2), 669-679

\title{
Adsorption of U(VI) from Aqueous Solution onto Hydrotalcite-Like Compounds
}

\author{
NGUYEN VAN SUC \\ Faculty of Chemical and Food Technology \\ Ho Chi Minh City University of Technical Education 01.vo Van Ngan \\ Thu Duc, Ho Chi Minh City, Vietnam \\ sucnv@hcmute.edu.vn
}

Received 18 August 2011; Accepted 4 Octobre 2011

\begin{abstract}
Uranium adsorption by the synthesized compound of magnesium aluminum hydroxide hydrate - layered double hydrotalcite (STH)-like compounds was studied. The calcinated STH was proven to be a highly effective in $\mathrm{U}(\mathrm{VI})$ adsorption in $\mathrm{pH}$ range from 6.5 to 7 . The time dependent experimental data were found to be fit to the pseudo-second-oder model. The equilibrium data have been modeled using Langmuir and Freundlich isotherms. The results showed that both model provide the best correlation with equilibrium data. The highest adsorption capacity, approximated 62.5 $\mathrm{mg} / \mathrm{g}$, was observed in the calcinated $\mathrm{STH}$ at $500{ }^{\circ} \mathrm{C}$. The positive value of enthalpy change indicated that adsorption reaction of U(VI) on STH was endothermic process. The regeneration experiments of STH using $0.1 \mathrm{M}$ $\mathrm{Na}_{2} \mathrm{CO}_{3}$ solution was successfully demonstrated multiple times without any significant effect on the initial adsorption capacity.
\end{abstract}

Keywords: Uranium, Adsorption, Hydrotalcite like compounds, Isotherms.

\section{Introduction}

Uranium pollution in aquatic environment has been a subject for extensive studies because of its high toxicity and radioactivity ${ }^{1-3}$. Recently published studies in animals and humans show effect of chronic uranium exposure at low levels in drinking water. Primary carcinogenic effect of uranium is on the kidneys ${ }^{4,5}$.

Although uranium could be naturally present from natural deposits leaching, it only poses a limited threat to environment. However, large amount of uranium is released from various human activities such as mill tailing discharge and nuclear industry emission as well as the use of fossil fuel in automobile and phosphate fertilizer in agriculture, which are also sources of uranium pollution ${ }^{2}$.

Clean uranium polluted water remains a challenge, in which, most of the efforts focus on uranyl ion adsorbents, which need to be effective in uranium removal as well as environmental friendly. Natural absorbents such as clays and minerals have been the subjects of many U(VI) adsorption studies ${ }^{6-10}$. Recently, a class of synthetic clay known as 
the magnesium aluminum hydroxide hydrate layered double hydroxides, or hydrotalcite-like compound, has been demonstrated as a potential adsorbent because of its high adsorption capacity with cationic and anionic species ${ }^{11-13}$. Moreover, this clay is easily synthesized from inexpensive chemicals. Those advantages indicate that synthesized hydrotalcite clay (STH) would be a potential adsorbent for U(VI), however, the lack of published data about $\mathrm{U}(\mathrm{VI})$ adsorption on STH hinders its usefulness. Therefore, our main goal of this study is to obtain some characteristic information on U(VI) adsorption by STH allowing a better use of STH for recovering and removal of uranium from aqueous solution..

\section{Experimental}

All chemicals used in this work were of analytical grade. The standard solution of uranium (1.0 mg.mL $\mathrm{mL}^{-1}$ ) was prepared by dissolving $0.10 \mathrm{~g}$ of uranium metal $(99.99 \%)$ in $15 \mathrm{~mL}$ of conc. $\mathrm{HNO}_{3}$ and evaporated to dryness on a water bath. The residue was dissolved with $10 \mathrm{~mL}$ of $1 \mathrm{M} \mathrm{HNO}_{3}$ and transferred to a $100 \mathrm{~mL}$ measuring flask. The solution was diluted with water to the mark and shaken well. The solution of arsenazo III $(0.07 \%)$ was prepared by dissolving $0.07 \mathrm{~g}$ of arsenazo III (Merck Co.) in $100 \mathrm{~mL}$ of $0.05 \mathrm{M} \mathrm{HCl}$ solution and kept in a polyethylene vessel. The mixture solution of $\mathrm{MgCl}_{2} \cdot 6 \mathrm{H}_{2} \mathrm{O}$ and $\mathrm{AlCl}_{3} \cdot 6 \mathrm{H}_{2} \mathrm{O}$ (solution A) was prepared by dissolving $29.02 \mathrm{~g}$ of $\mathrm{MgCl}_{2} \cdot 6 \mathrm{H}_{2} \mathrm{O}$. and $14.48 \mathrm{~g}$ of $\mathrm{AlCl}_{3} \cdot 6 \mathrm{H}_{2} \mathrm{O}$ (Merck Co.) in $200 \mathrm{~mL}$ of distilled water. The mixture solution of $\mathrm{NaOH}$ and $\mathrm{Na}_{2} \mathrm{CO}_{3}$ (solution $\mathrm{B}$ ) was prepared by dissolving $64.0 \mathrm{~g}$ of $\mathrm{NaOH}$ and $11.44 \mathrm{~g} \mathrm{Na}_{2} \mathrm{CO}_{3}$ (Merck Co.) in $4 \mathrm{~L}$ of distilled water.

\section{Preparation of STH}

The STH was prepared by the co precipitation method ${ }^{15}$. The procedure of the method was carriedout as follows: the solution A was slowly added into the solution B under continuously stirring condition. $\mathrm{pH}$ of the mixture was maintained from 9 to 10 by adjusting with $\mathrm{HCl}$ or $\mathrm{NaOH}$ diluted solutions. The precipitates were separated by centrifuging and washed several time with distilled water. The precipitates were mixed with $200 \mathrm{~mL}$ of distilled water and kept in an oven at $80{ }^{\circ} \mathrm{C}$ for $48 \mathrm{~h}$ and then separated from the liquid phase by centrifuging and dried at $100{ }^{\circ} \mathrm{C}$ for $24 \mathrm{~h}$. The dried solid was ground to fine powder using a manual hand grinding mills and stored in closed container, ready for use. About $5 \mathrm{~g}$ each of STH were calcinated at individual temperature $\left(100,200,300,400\right.$ and $\left.500{ }^{\circ} \mathrm{C}\right)$ for $3 \mathrm{~h}$ The calcinated STHs at different temperature were labeled as STH-100, STH-200, STH300, STH-400 and STH-500, in which the number indicates the calcination temperature.

The synthesized STH was characterized as single crystal of $\mathrm{Al}_{2} \mathrm{O}_{3}$ and $\mathrm{Mg}_{2} \mathrm{O}$ using Xray diffraction spectra, which was recorded with Sciffert 3000 using $\mathrm{CuK}_{\alpha}$ radiation. The scanning electron microscope (SEM) surface image was obtained using HITACHI S - $3400 \mathrm{~N}$. Compositions of $\mathrm{MgO}$ and $\mathrm{Al}_{2} \mathrm{O}_{3}$ in $\mathrm{STH}$ were determined using X-ray fluorescence (XRF) using Phillips PW 1480 spectrometer. The BET surface areas of calcinated STH samples were measured by $\mathrm{N}_{2}$-adsorption using micromeritics ASAP 2000.

\section{Uranium analysis}

Determination of U(VI) in the liquid phase after equilibriums was based on measuring the color complex of U(VI) with arsenazo III in the medium of $10^{-3} \mathrm{M} \mathrm{HClO}_{4}{ }^{14}$. A test solution containing U(VI) was placed into a $50 \mathrm{~mL}$ measuring flash. $1 \mathrm{~mL}$ of $0.07 \%$ arsenazo III and $10 \mathrm{~mL}$ of $3 \mathrm{M} \mathrm{HClO}_{4}$ was added. The mixture was shaken for two min and $3 \mathrm{M} \mathrm{HClO}_{4}$ solution then added to the measuring volume. The mixture was shaken for three min. The absorbance of the absorbing solution was measured at $650 \mathrm{~nm}$ using a Libra S32 Perkin Elmer spectrophotometer. Uranium content in the test solution was determined from a calibration curve, which was constructed using a uranium standard solution. 


\section{Adsorption studies}

Batch adsorption experiments were conducted in a series Erlenmeyer flasks containing $0.1 \mathrm{~g}$ of STH with $50 \mathrm{~mL}$ aqueous solution of U(VI) of desired initial concentration $(10-100 \mathrm{mg} / \mathrm{L})$ at constant $\mathrm{pH}$ of 6.5 . The reaction solutions were shaken in a water bath using an Innova model 3000 lab shaker at $30 \pm 1{ }^{0} \mathrm{C}$. The flasks containing reaction solution were tightly closely to reduce dissolution of $\mathrm{CO}_{2}$ from air. Samples were withdrawn after a definite time interval and liquid phase is separated by centrifuging. Similar experiments were repeated with varying solution $\mathrm{pH}$ and temperature. Effect of individual calnination temperature of STH was obtained by shaking $0.1 \mathrm{~g}$ of the adsorbent in $50 \mathrm{~mL}$ of $100 \mathrm{mg} / \mathrm{L}$ $\mathrm{U}(\mathrm{VI})$ at $\mathrm{pH}$ 6.5. Shaking time for reaching to equilibrium adsorption was selected from previous experiments. For study of regeneration ability of STH, batch experimental mode was performed in a glass beaker containing $0.1 \mathrm{~g}$ of exhausted STH used in previous experiments and $20 \mathrm{~mL}$ of $0.1 \mathrm{M} \mathrm{Na}_{2} \mathrm{CO}_{3}$ solution. The mixture was mixed by a mechanical mixer for $120 \mathrm{~min}$. The solid phase was then separated by centrifuging and washed with distilled water until free of $\mathrm{CO}_{3}{ }^{2-}$. The resulting STH was dried at $80{ }^{0} \mathrm{C}$ in a furnace for three hours. This step was considered as a first cycle. In the next cycle, resulting STH obtained in the first cycle was placed in a $100 \mathrm{~mL}$ beaker containing $50 \mathrm{~mL}$ of uranium solution $(100 \mathrm{mg} \mathrm{U} / \mathrm{L})$. $\mathrm{pH}$ of the reaction solution was adjusted to 6.5 . The mixture was shaken for $60 \mathrm{~min}$. After equilibrium, the solid phase was separated by centrifuging. The similarly experiments of sorption/ desorption were carried out in the third and fourth regeneration cycles.

Percentage adsorption of U(VI) on STH and the adsorption capacity defined as amount of adsorbate per unit mass of adsorbent is calculated by formulas: is calculated by relationships:

$$
\% \text { adsorption }=\frac{C_{i}-C_{e}}{C_{i}} \times 100
$$

and

$$
q_{e}=\frac{C_{i}-C_{e}}{C_{i}} \times \frac{V}{m}
$$

Where, $C_{i}$ is initial concentration of $U(V I)$ in $m g . L^{-1}$ and $C_{e}$ is concentration of $U(V I)$ at equilibrium $\left(\mathrm{mg} \cdot \mathrm{L}^{-1}\right), \mathrm{V}$ is volume of adsorbate $\left(\mathrm{dm}^{3}\right), \mathrm{m}$ is the mass of adsorbent $(\mathrm{g})$.

\section{Results and Discussion}

\section{Characteristics of STH}

Table 1 shows the composition and ratios of Mg and Al in STH. The surface areas of STH are also included in table 1.Ratios of $\mathrm{Mg}$ and $\mathrm{Al}$ obtained in STH prepared by our method was found to be $2: 1$ and in an agreement with those, which had been reported ${ }^{15}$. The surface area of STH were observed to increase with increasing calcination temperature. The highest value of the surface area of calcinated STH at $500^{\circ} \mathrm{C}$ was found to be $182 \mathrm{~m}^{2} / \mathrm{g}$. The increase of the surface area of calcinated STH may be due to dehydroxylation and loss of interlayer anions, which cause a collapse of the layered structure. The SEM imagine of STH gives in Figure 1, which is shown that the amorphous and rough surface of the STH was observed. X-ray diffraction (XRD) patterns of noncalcinated STH and calcinated STH (STH-500) are shown in Figure $2 \mathrm{a}$ and $2 \mathrm{~b}$, respectively. The diffraction peaks of noncalcinated STH (Figure 2a) are typical of the layered double hydroxide structure with the characteristic basal spacing $\mathrm{d}=7.73 \AA$, which corresponds to interlayer $\mathrm{CO}_{3}{ }^{2-16}$. On the contrary, the peaks at 7.73 and $3.87 \AA$ in X-ray diffraction pattern of the canlcinated STH (Figure $2 b$ ) are not present. At 
high temperature of calcinations, $\mathrm{CO}_{3}{ }^{2-}$ in the interlayer of STH was completely removed and the layered structure was destroyed ${ }^{16}$. It means that heating of STH leads to yield a periclase $\mathrm{MgO}$ phase in addition to amorphous aluminum.

Table 1. Characteristic of synthesized STH.

\begin{tabular}{cccccccc}
\hline \multirow{2}{*}{$\mathrm{Al}_{2} \mathrm{O}_{3}, \%$} & \multirow{2}{*}{$\begin{array}{c}\mathrm{MgO}, \\
\%\end{array}$} & $\mathrm{Ratio}$ & \multicolumn{5}{c}{ Surface areas, $\mathrm{m}^{2} / \mathrm{g}$} \\
\cline { 5 - 8 } & & & $\begin{array}{c}\text { Noncalcinated } \\
\text { STH }\end{array}$ & \multicolumn{4}{c}{ Calcinated STH, ${ }^{0} \mathrm{C}$} \\
\cline { 5 - 8 } & & & 200 & 300 & 400 & 500 \\
\hline 0,70 & 39,08 & $2: 1$ & 158 & 162 & 177 & 180 & 182 \\
\hline
\end{tabular}

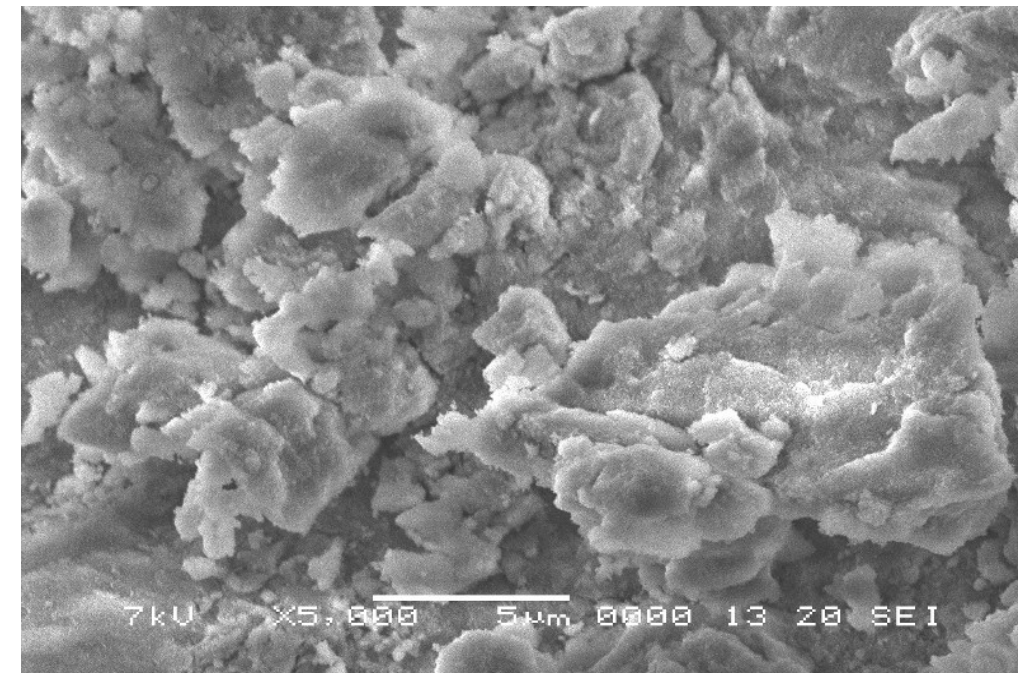

Figure 1. SEM imagine of the synthetic STH.

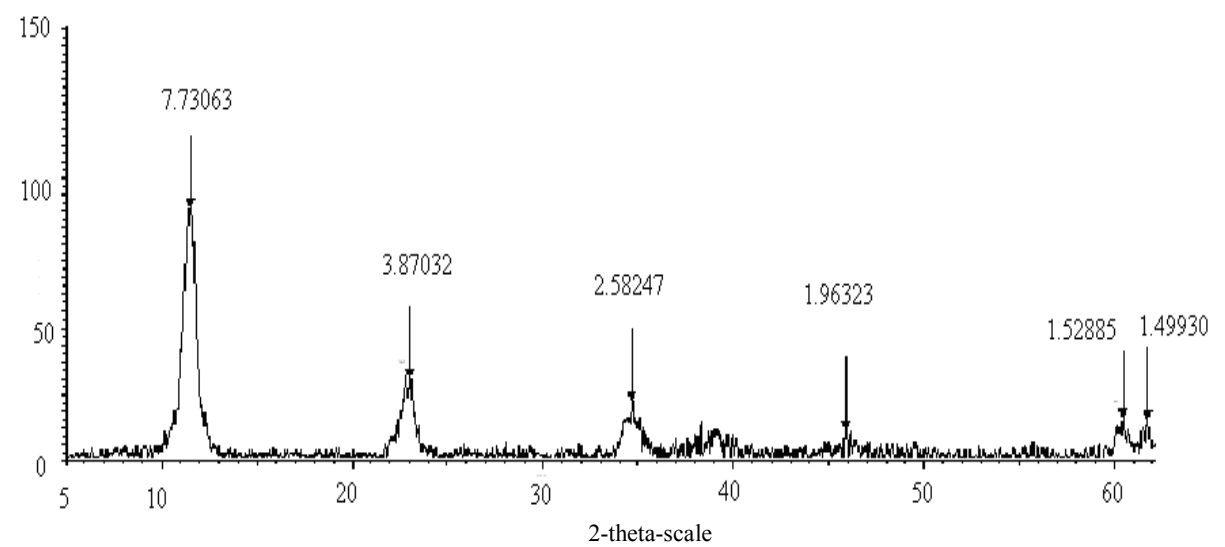

Figuire 2a. The diffraction spectra of the noncalcinated STH. 


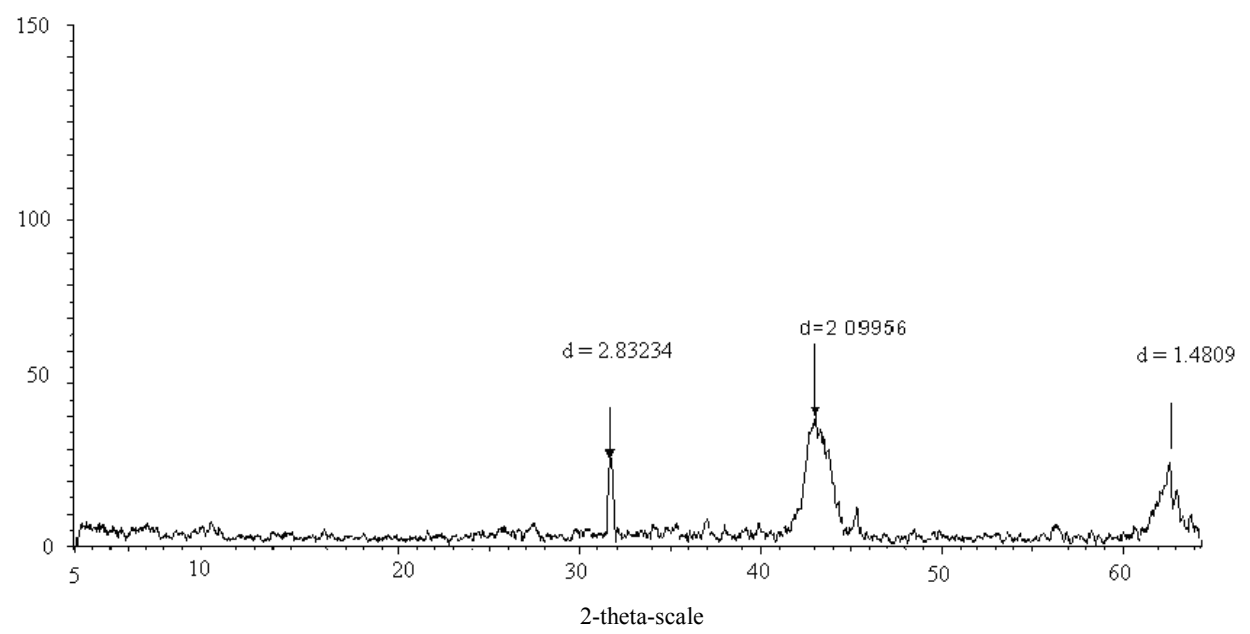

Figure 2b. The diffraction spectra of the calcinated STH -500.

\section{Effect of contact time}

The time dependence curves of U(VI) removal are illustrated in Figure 3. It can be seen that percentage uptake of U(VI) increases with the elapse time. At initial contact time (up to $30 \mathrm{~min}$ ), adsorption rate of U(VI) took place rapidly and thereafter the rate of adsorption was found to be slow. There is only somewhat different in adsorption rate of STH with different concentration of $\mathrm{U}(\mathrm{VI})$. Initial slow rate was found when concentration of U(VI) is about $100 \mathrm{mg} / \mathrm{L}$. This may be due to competition between uranium ions for diffusing onto the adsorbent surface. However, the equilibrium adsorption with maximum adsorption capacity (in percentage) in all different concentration of $U(V I)$ was reached more than $99 \%$ at $120 \mathrm{~min}$. This time was used for the other experiments in this study.

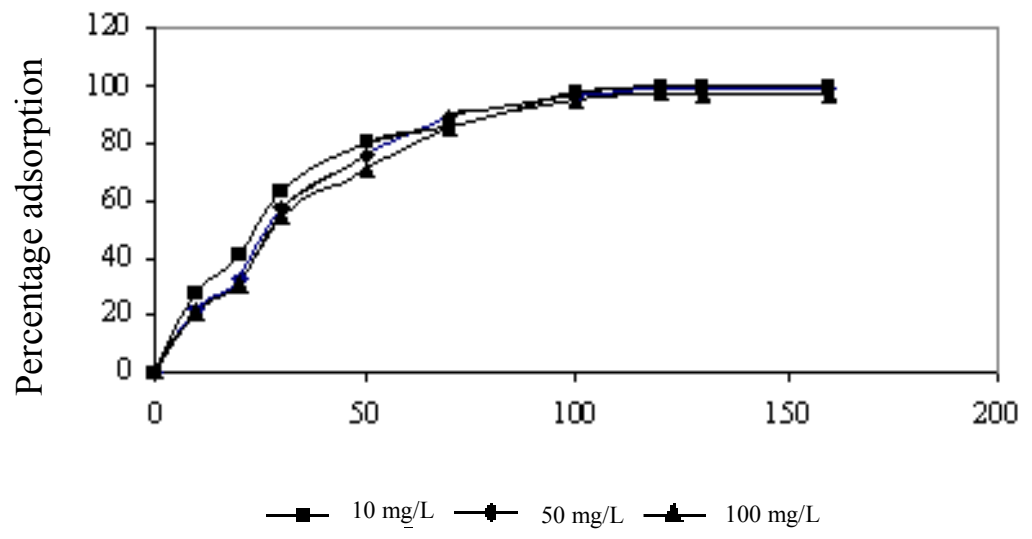

Figure 3. The effect of the contact time on the adsorption of U(VI) by STH.

\section{Effect of $\mathrm{pH}$}

Figure 4 illustrates the effect of $\mathrm{pH}$ on $\mathrm{U}(\mathrm{VI})$ adsorption. It can be seen that adsorption of $\mathrm{U}(\mathrm{VI})$ by $\mathrm{STH}$ is a function of $\mathrm{pH}$ values. The maximum adsorption percentage achieved more than $97.0 \%$ at $\mathrm{pH}$ from 6.5 to 7 and reduced to $85.5-80 \%$ and lower at $\mathrm{pH} \geq 8$. At $\mathrm{pH}$ $\leq 5$, the percentage adsorption is rapidly reduced for all concentration used in this test. This adsorption behaviors can be explained by the existence of different uranium species which may have responsibility to uptake U(VI) by STH. 


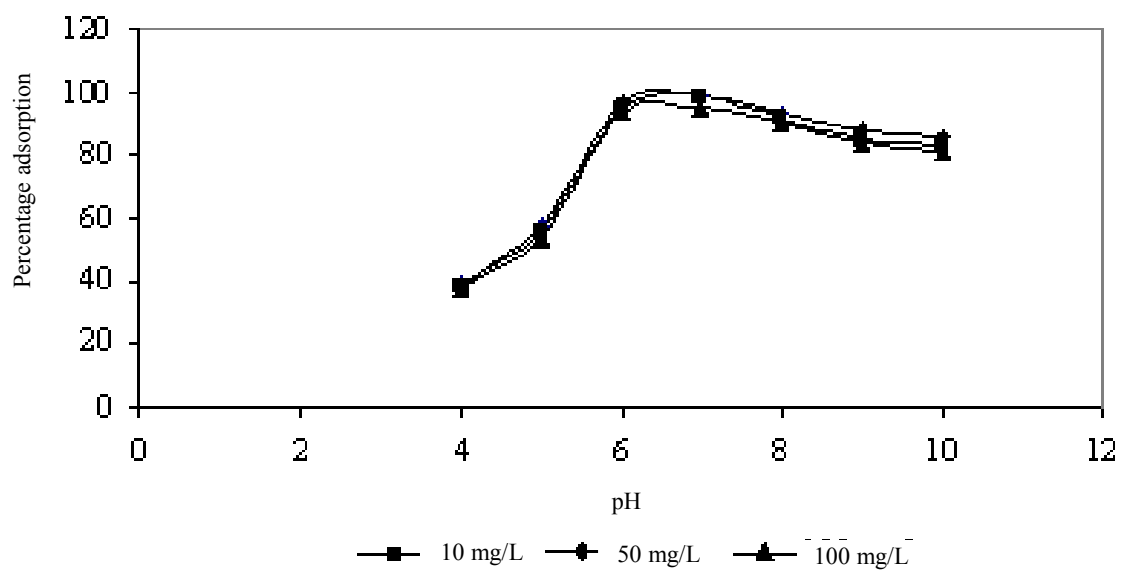

Figure 4. The effect of $\mathrm{pH}$ on the $\mathrm{UO}_{2}{ }^{2+}$ adsorption capacity by $\mathrm{STH}$.

In the range of $\mathrm{pH} \leq 5, \mathrm{U}(\mathrm{VI})$ primarily exists in the cationic form as $\mathrm{UO}_{2}{ }^{2+}{ }^{17}$, which competes against $\mathrm{H}^{+}$ions for adsorption process. Increasing of high $\mathrm{H}^{+}$ion concentration leads to gradually protonation of the adsorbent surface. Therefore, the positive charge uranyl ions are repelled from adsorbed sites.

In the slight acid and neutral medium ( $\mathrm{pH} 6.5$ - 7), the competition of $\mathrm{H}^{+}$ions is negligible. Furthermore, in this $\mathrm{pH}$ range, $\mathrm{U}(\mathrm{VI})$ primarily exists in the form of hydrolyzed ion such as $\mathrm{UO}_{2}(\mathrm{OH})^{+},\left(\mathrm{UO}_{2}\right)_{2}(\mathrm{OH})_{2}{ }^{2+}$ and $\left(\mathrm{UO}_{2}\right)_{3}(\mathrm{OH})_{5}{ }^{+}$which have low ionic charge that causes decreasing in secondary solvation energy ${ }^{17}$. This phenomenon makes $\mathrm{U}(\mathrm{VI})$ in the form of $\left(\mathrm{UO}_{2}\right)_{3}(\mathrm{OH})_{5}{ }^{+}$easily diffusing to the sorption sites of the adsorbent.

At $\mathrm{pH} \geq 8, \mathrm{U}(\mathrm{VI})$ primarily exists in the anionic complexes with $\mathrm{OH}^{-}$and $\mathrm{CO}_{3}{ }^{2-}$ (formed by dissolution of $\mathrm{CO}_{2}$ from air) such as $\left(\mathrm{UO}_{2}\right) \mathrm{CO}_{3}(\mathrm{OH})_{3}{ }^{-}, \mathrm{UO}_{2}\left(\mathrm{CO}_{3}\right)_{2}{ }^{2-}, \mathrm{UO}_{2}\left(\mathrm{CO}_{3}\right)_{3}{ }^{4-}$, etc. These complexes are very stable in the solution. The existence of the stable carbonate complexes of $\mathrm{U}(\mathrm{VI})$ with $\mathrm{CO}_{3}{ }^{2-}$ and $\mathrm{OH}^{-}$in the alkaline medium leads to reducing adsorption capacity of the STH .

\section{Adsorption kinetics}

In this research, two kinetic models used for fitting experimental data are the pseudo-firstorder, pseudo-second order models ${ }^{8}$. The pseudo-first order model:

$$
\log \left(q_{e}-q_{t}\right)=\log q_{e}-\frac{k_{1}}{2.303} t
$$

Where, $\mathrm{k}_{1}$ is the pseudo-first-order constant $\left(\mathrm{min}^{-1}\right), \mathrm{q}_{\mathrm{t}}$ is amount adsorbed at time $\mathrm{t}(\mathrm{mg} / \mathrm{g})$ and $\mathrm{q}_{\mathrm{e}}$ is the amount adsorbed at equilibrium $(\mathrm{mg} / \mathrm{g})$. The pseudo-second-order model:

$$
\frac{t}{q_{t}}=\frac{1}{k_{2} q_{e}^{2}}+\frac{1}{q_{e}} t
$$

Where, $\mathrm{k}_{2}$ is the pseudo-second-order constant (g/mg.min). The plots of $\log \left(\mathrm{q}_{\mathrm{e}}-\mathrm{q}_{\mathrm{t}}\right)$ from Eq.(3) and $t / q_{t}$ from Eq.(4) against $t$ give a linear relationship, which allow to calculate $\mathrm{k}_{1}, \mathrm{k}_{2}$ and predict $\mathrm{q}_{\mathrm{e}}$. The linear plots for the pseudo-first-odder and the pseudo-secondorder models are presented in Figure 5 and 6, respectively. Table 2 lists the prameters of two models. The correlation coefficients values, $\mathrm{R}^{2}$, of the pseudo-first-order and the pseudo-second-order models were found to be 0.987 and 0.999 , respectively. These values are very high for both models. However, there is only an agreement between 
$\mathrm{q}_{\mathrm{e}, \text { exp }}$, experimental and $\mathrm{q}_{\mathrm{e}, \mathrm{th}}$, predicted values for the pseudo-second-model. Thus, the best fit was achieved by the pseudo-second-order model for the U(VI) adsorption by STH.

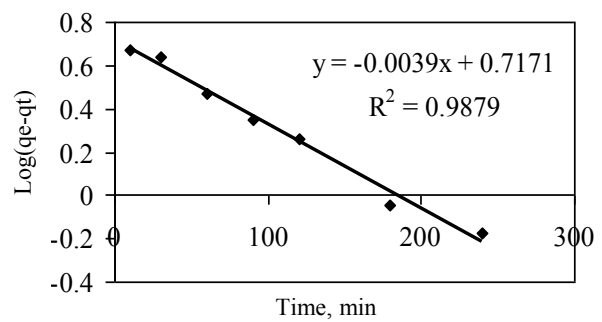

Figure 5. Plots of pseudo-first-order equation for $\mathrm{U}(\mathrm{VI})$ adsorption $([\mathrm{U}]=20 \mathrm{mg} / \mathrm{L}$, $\mathrm{pH}=6.5, \mathrm{~T}=303 \mathrm{~K})$.

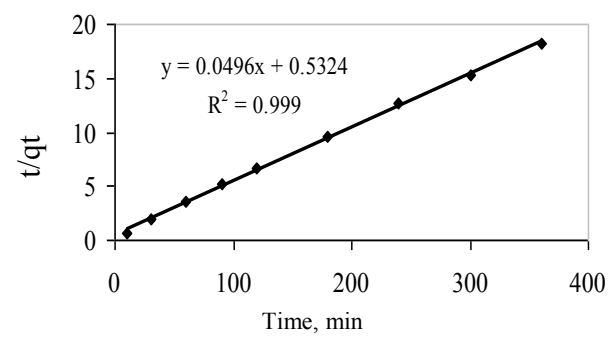

Figure 6. Plots of pseudo-second-order equation for $\mathrm{U}(\mathrm{VI})$ adsorption $([\mathrm{U}]=20 \mathrm{mg} / \mathrm{L}$, $\mathrm{pH}=6.5, \mathrm{~T}=303 \mathrm{~K})$.

Table 2. Parameters of pseudo-second-order model for U(VI) adsorption.

\begin{tabular}{|c|c|c|c|c|c|c|}
\hline \multicolumn{3}{|c|}{ Pseudo-first-order model } & \multicolumn{4}{|c|}{ Pseudo-second-order mode } \\
\hline $\mathrm{k}_{1}$ & $\mathrm{q}_{\mathrm{e}, \exp }, \mathrm{mg} / \mathrm{g} \quad \mathrm{q}_{\mathrm{e}, \mathrm{th}}, \mathrm{mg} / \mathrm{g}$ & $\mathrm{R}^{2}$ & $\mathrm{k}_{2}$ & $\mathrm{q}_{\mathrm{e}, \exp }, \mathrm{mg} / \mathrm{g}$ & $\mathrm{q}_{\mathrm{e}, \mathrm{th}}, \mathrm{mg} / \mathrm{g}$ & $\mathrm{R}^{2}$ \\
\hline 0.033 & 19.7 & 0.9879 & 0.0183 & 19.70 & 20.1 & 0.999 \\
\hline
\end{tabular}

\section{Adsorption Isotherm}

The experimental equilibrium data for the adsorption of U(VI) by STH are described according to the Langmuir and Freundlich models ${ }^{18}$ : The linear form of Langmuir model:

$$
\frac{C_{e}}{q_{e}}=\left(\frac{1}{K_{l} Q_{\max }}\right)+\left(\frac{C_{e}}{Q_{\max }}\right)
$$

Where, $\mathrm{q}_{\mathrm{e}}$ is adsorption capacity $(\mathrm{mg} / \mathrm{g}), \mathrm{C}_{\mathrm{e}}$ is uranium concentration in liquid phase after equilibration $(\mathrm{mg} / \mathrm{L}), \mathrm{K}_{1}$ is Langmuir constant related to the binding energy between the adsorbent and the adsorbate, $\mathrm{L}_{\mathrm{mg}} \mathrm{m}^{-1}$ and $\mathrm{Q}_{\max }$ is maximum adsorption capacity (mg.g $\mathrm{g}^{-1}$ ). The linearized form of the Freundlich model:

$$
\log q_{e}=\log K_{f}+1 / n \log C_{e}
$$

Where, $\mathrm{K}_{\mathrm{f}}$ is the Freundlich constant $(\mathrm{g} / \mathrm{L}), \mathrm{n}$ is the a measure of the adsorption intensity, $\mathrm{C}_{\mathrm{e}}$ and $\mathrm{q}_{\mathrm{e}}$ have the same definition as stated in equation 4 .

The values of $\mathrm{K}_{1}$ and $\mathrm{Q}_{\max }$ in Eq. 5 and $\mathrm{K}_{\mathrm{f}}$ and $\mathrm{n}$ in Eq. 6 can be calculated from the slope and the intercept of linear plots $\mathrm{Ce} / \mathrm{q}_{\mathrm{e}}$ and $\log \mathrm{q}_{\mathrm{e}} v s . \mathrm{C}_{\mathrm{e}}$, respectively. Figures 7 and 8 show the comparative of Langmuir, Freundlich isotherms with correlation coefficient values 
are 0.9905 and 0.9997 , respectively. From the results, it can be seen that the equilibrium adsorption capacity for both models, $\mathrm{q}_{\mathrm{e}}$ increased with the increase in U(VI) concentration.

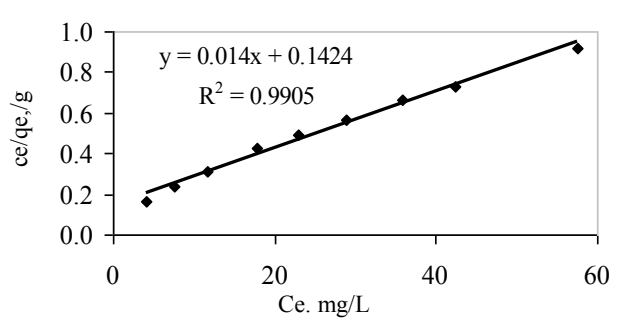

Figure 7. Langmuir adsorption isotherm of $\mathrm{U}(\mathrm{VI})$ onto STH $(\mathrm{pH}=6.5, \mathrm{~T}=303 \mathrm{~K})$.

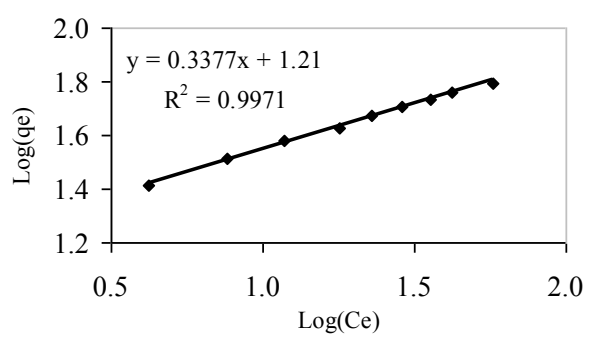

Figure 8. Freundlich adsorption isotherm of $\mathrm{U}(\mathrm{VI})$ onto $\mathrm{STH}(\mathrm{pH}=6.5, \mathrm{~T}=303 \mathrm{~K})$.

Table 3. Langmuir and Freundlich isotherm constants.

\begin{tabular}{cccccc}
\hline \multicolumn{3}{c}{ Langmuir model } & \multicolumn{3}{c}{ Freundlich model } \\
\hline $\mathrm{K}_{1}$ & $\mathrm{Q}_{\max }$ & $\mathrm{R}^{2}$ & $\mathrm{~K}_{\mathrm{f}}$ & $1 / \mathrm{n}$ & $\mathrm{R}^{2}$ \\
0.131 & 62.5 & 0.9905 & 22.6 & 0.378 & 0.997 \\
\hline
\end{tabular}

The linear type of the Langmuir model at different temperature is shown in Figure 9. The values of parameters in Langmuir model were determined and reported in Table 4. From results, it was found that the adsorption of U(VI) by STH is increased with increasing temperature. To determine Gibbs free energy $\left(\Delta \mathrm{G}^{0}\right)$, standard enthalpy change $\left(\Delta \mathrm{H}^{0}\right)$, and standard entropy change $\left(\Delta S^{0}\right)$ of the adsorption reactions between U(VI) and STH at different temperature, the thermodynamical equations ${ }^{17}$ were used:

$$
\begin{gathered}
\ln K_{l}=A-\frac{\Delta H^{0}}{R T} \\
\ln K_{l}=-\frac{\Delta G^{0}}{R T} \\
\Delta S^{0}=\frac{\left(\Delta H^{0}-\Delta G^{0}\right)}{T}
\end{gathered}
$$

Where, $\mathrm{R}$ is universal gas constant $(8.314 \mathrm{~J} / \mathrm{mol} . \mathrm{K}), \mathrm{T}$ is absolute temperature $(\mathrm{K})$. Figure 10 shows the linear plot of $\operatorname{lnK}_{1}$ against constant $1 / \mathrm{T}$ of the equation (7). The value of enthalpy change $\left(\Delta \mathrm{H}^{0}\right)$ for the adsorption of $\mathrm{U}(\mathrm{VI})$ by STH could be obtained from the slope of the plot. The values of the Gibbs free energy $\left(\Delta G^{0}\right)$ and the standard entropy change $\left(\Delta S^{0}\right)$ were calculated using equations (8) and (9). The thermodynamic parameters obtained in this study are given in Table 4 . 


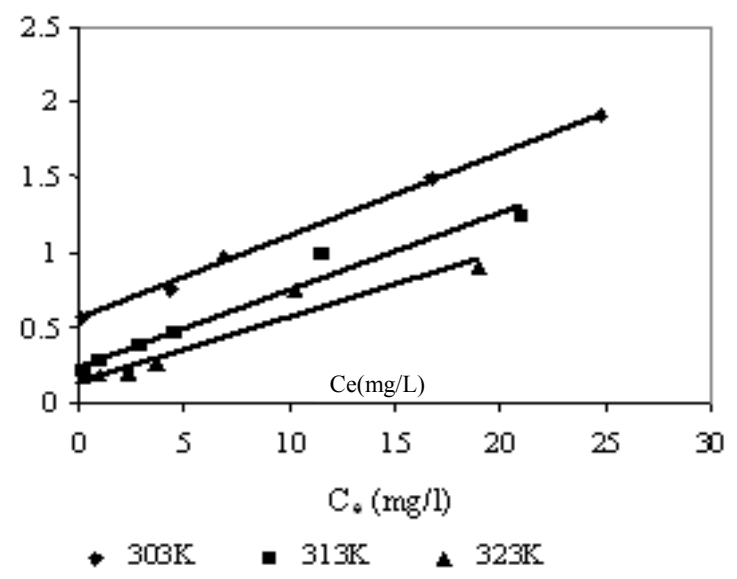

Figure 9. The linear type of the Langmuir model at different temperature.

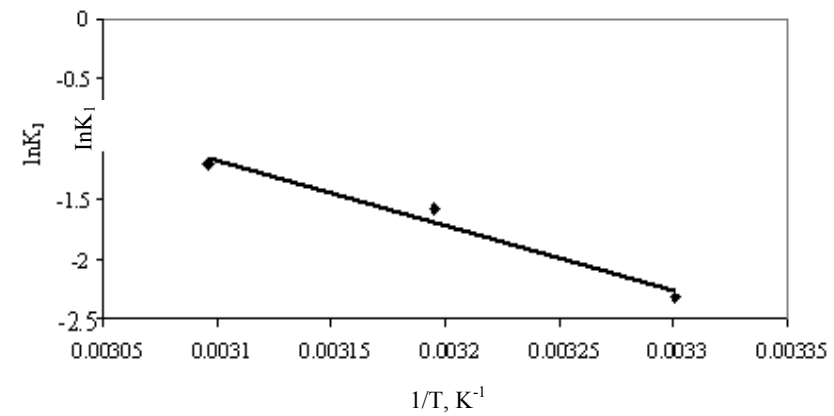

Figure 10. The variation of the Langmuir constant with temperature.

Table 4. Parameters of Langmuir equation for the U(VI) adsorption.

\begin{tabular}{cccc}
\hline $\mathrm{T}, \mathrm{K}$ & $\mathrm{K}_{1,} \mathrm{~L} / \mathrm{mg}$ & $\mathrm{A}, \mathrm{mg} / \mathrm{g}$ & $\mathrm{R}^{2}$ \\
\hline 303 & 0.131 & 18.281 & 0.997 \\
313 & 0.205 & 19.762 & 0.963 \\
323 & 0.296 & 23.09 & 0.933 \\
\hline
\end{tabular}

Table 5. The thermodynamic parameters for the adsorption of U(VI) on STH.

\begin{tabular}{cccc}
\hline $\mathrm{T}, \mathrm{K}$ & $\Delta \mathrm{H}, \mathrm{kJ} / \mathrm{mol}$ & $\Delta \mathrm{S}, \mathrm{J} / \mathrm{mol} . \mathrm{K}$ & $\Delta \mathrm{G}(\mathrm{kJ} / \mathrm{mol})$ \\
\hline 303 & 45.26 & 130 & 5.87 \\
313 & & 131 & 4.03 \\
323 & & 130 & 3.19 \\
\hline
\end{tabular}

The positive values of enthalpy change $\left(\Delta \mathrm{H}^{0}\right)$ indicates the endothermic nature of the adsorption process of $\mathrm{U}(\mathrm{VI})$ by STH. Positive values of Gibbs free energy $\left(\Delta \mathrm{G}^{0}\right)$ indicate that the adsorption process depended on temperature. As shown in results, $\Delta G^{0}$ values 
obtained are very small and decrease with increasing temperature. The adsorption of U(VI) by STH. The values of the entropy change $\left(\Delta S^{0}\right)$ are positive and remain almost constant with temperature. This reflects the affinity of the STH for U(VI) and suggest increased randomness at the adsorbent / solution surface during the adsorption.

\section{Effect of calcination temperature}

Based on the Langmuir model, the maximum adsorption capacities for U(VI) by STH calcinated at 100,200,300, 400 and $500{ }^{\circ} \mathrm{C}$ were found to be 23.0, 24.8, 25.1, 47.8 and $51.2 \mathrm{mg} / \mathrm{g}$, respectively. There are two factors that may have contribution to the increase of the adsorption capacity of calcinated STH: (i) the high available sorption sites due to high surface areas of the calcinated STH; (ii) the structural memory effect of hydrotacite. According to Erickson et $a l^{16}$ when exposition to water, the calcinated STH induces the reconstruction of its original structure by taking anion from aqueous solutions. It means that, anionic complexes of $\mathrm{U}(\mathrm{VI})$ with $\mathrm{OH}^{-}$and $\mathrm{CO}_{3}{ }^{2-}$ such as $\left(\mathrm{UO}_{2}\right) \mathrm{CO}_{3}(\mathrm{OH})_{3}{ }^{-}, \mathrm{UO}_{2}\left(\mathrm{CO}_{3}\right)_{2}{ }^{2-}$, $\mathrm{UO}_{2}\left(\mathrm{CO}_{3}\right)_{3}{ }^{4-}$ at $\mathrm{pH} \geq 6$ will participate in the reconstruction of the calcinated $\mathrm{STH}$, and enhance the adsorption capacity.

\section{Regeneration of STH}

From characteristics of the STH including the high adsorption capacity, the structural memory effect and the stability of the anion carbonate complexes of U(VI), the $0.1 \mathrm{M}$ $\mathrm{Na}_{2} \mathrm{CO}_{3}$ solution was selected for regeneration of the noncalcinated STH. The results of four regenerations cycles of the exhausted STH are presented in Table 5. The percentage adsorption was only slightly reduced from the third and the fourth cycles. From the results obtained, it can be concluded that STH could be reused for recovery and removal of U(VI) in aqueous solution.

Table 6. The generation results of the exhausted STH.

\begin{tabular}{ccccc}
\hline Number of Regeneration cycle & 1 & 2 & 3 & 4 \\
U (VI) adsorption capacity, \% & 98.3 & 98.0 & 97.5 & 97.2 \\
\hline
\end{tabular}

\section{Conclusion}

Synthesized clay (STH) was prepared with high adsorption capacity with U (VI). There was difference adsorption capacity between different calcination temperatures of STH. The $\mathrm{pH}$ values were also effect on adsorption capacity of STH. The suitable $\mathrm{pH}$ ranges for uranium adsorption by STH is from 6.5 to 7 . The time dependent experimental data were found to be fit to the pseudo-second-oder model. The Langmuir and Freundlich models s showed that both model provide the best correlation with equilibrium data. The measured adsorption isotherm at the different temperature were found to be fit to the Langmuir model with correction coefficients, $\mathrm{R}^{2}=0.997,0.963$ and 0.933 at $303 \mathrm{~K}, 313 \mathrm{~K}$ and $323 \mathrm{~K}$ respectively. From Langmuir model, the adsorption maximum capacity of STH was calculated. It is 51.2 mg U(I) per $g$ of STH. For regeneration studies, the results obtained were shown that the adsorption capacity is only slightly reduced after fourth cycle. From results obtained, it could be concluded that the STH is a potential adsorbent for removal of U (VI) in contaminated water as well as from wastewater containing uranium. 


\section{Acknowledgment}

I would like to thank Ms. Le Thi Bach Hue for giving the help and co-operation needed to complete the experiment in this work.

\section{References}

1. $\quad$ Alirezadehn N and Garsasbi H, Iran J Radiat Res., 2003, 1, 139.

2. Kurttio P, Renal Effects of Uranium in Drinking Water, Environ. Health Perspectives. 2002, 110, 337.

3. Miller A C, Xu J, Stewart M, Brooks K, Hodge S, Shi L, Page N and McClain D, Radiation Protection Dosimetry, 2002, 99, 275.

4. Igarashi Y, Yamakawa A and Ikeda N, Plutonium and Uranium in Japanese human Tissues, Radioisotopes, 1987, 36, 433.

5. Hakonson-Hayes A C, Fresquez P R, Whicker F W, J Environ Radioact., 2002, 59, 29.

6. Olmez Aytas S A.and Eral M, J Radioanal Nucl Chem., 2004, 260, 119.

7. Deniz A, Julide H and Resat Apak; Radiochim Acta, 2006, 94, 835.

8. Konstantinou M, Demetriou A and Pashalidis I, J Global NEST, 2007, 9, 229.

9. Dona R, J Chem Thermodynamics, 2009, 41, 829.

10. Patricia T A, Env Eng Sci., 2009, 26, 691.

11. Sadet Y, Turkish J Eng Env.Sci., 2004, 28, 41.

12. Kazumichi K, Jun Y, Yoshiaki K, Toshiro Y, Masahiro N, Tae-Gwan L, Chemosphere, 2006, 62, 45.

13. Gabriela C, Simona R, Gabriela C and Ion B, Desalination, 2008, 223, 243.

14. Shjo Y and Sakai K, Water Japan Anal., 1982, 31, 395.

15. Jong H, Seog W R and Duk-Young J, Bull Korean Chem Soc., 2005, 26, 250.

16. Erickson K L, Bostrom T E and Frost R L, SEM, Mater Lett., 2004, 59, 226 .

17. Ho CH and Doern D.C, Can J Chem., 1985, 63, 1100.

18. Yavus Ö, Altunkaynak Y and Guzel F, Water Res., 2003, 37, 948. 


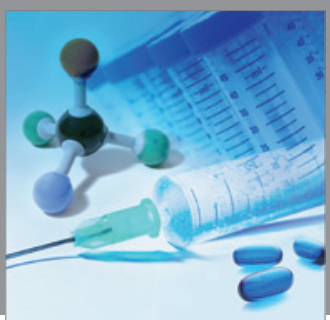

International Journal of

Medicinal Chemistry

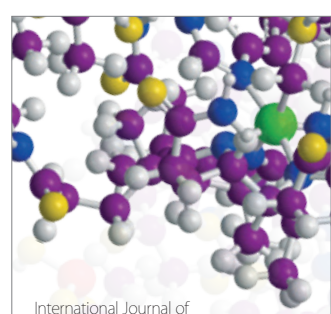

Carbohydrate Chemistry

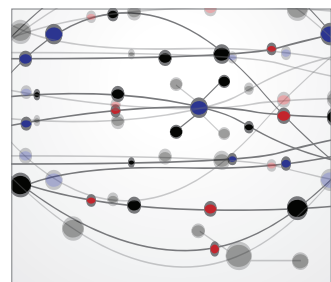

The Scientific World Journal
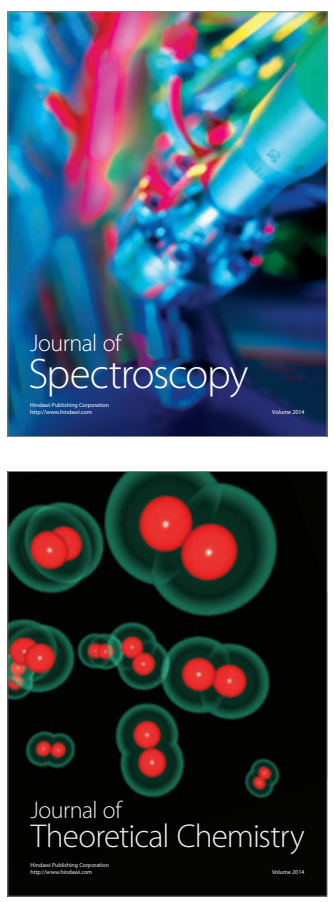
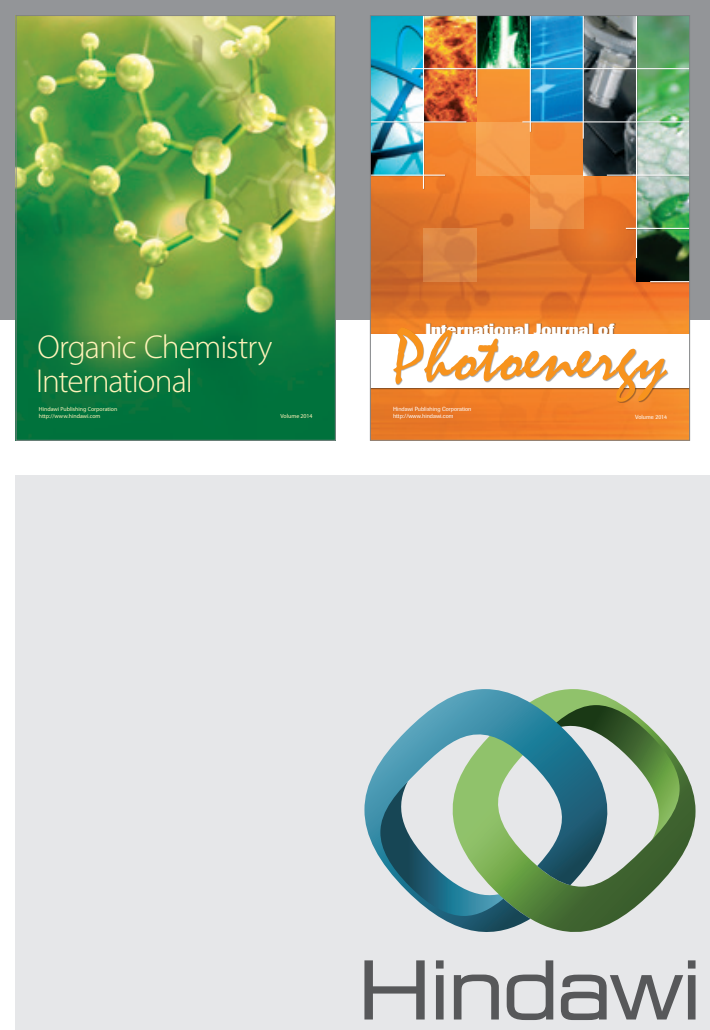

Submit your manuscripts at

http://www.hindawi.com
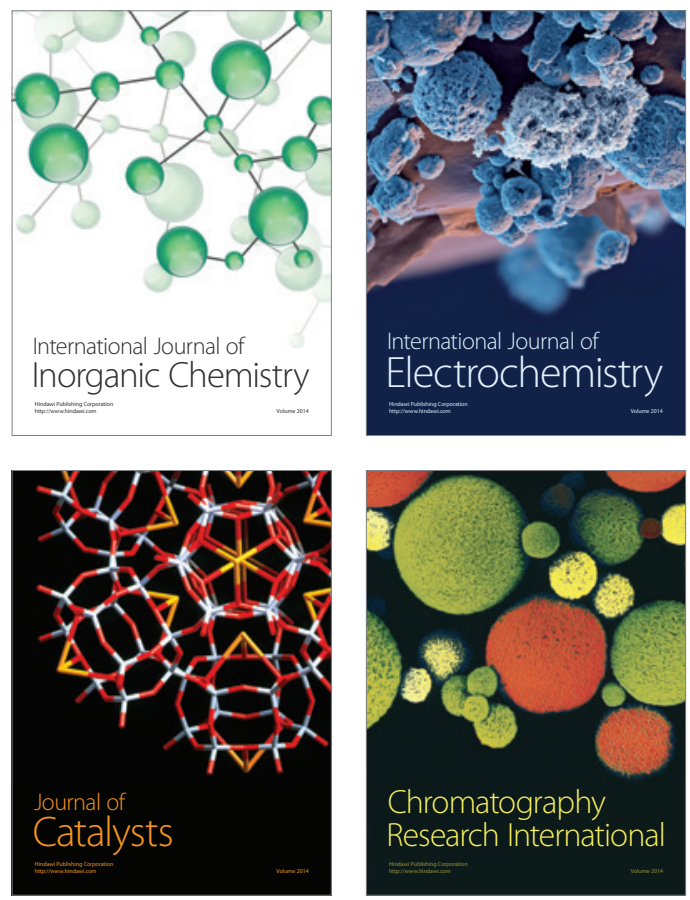
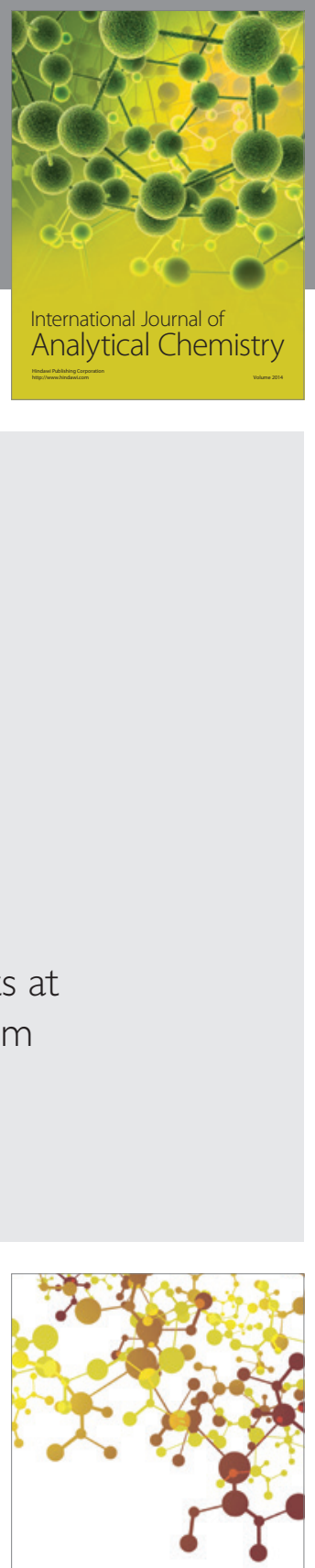

Journal of

Applied Chemistry
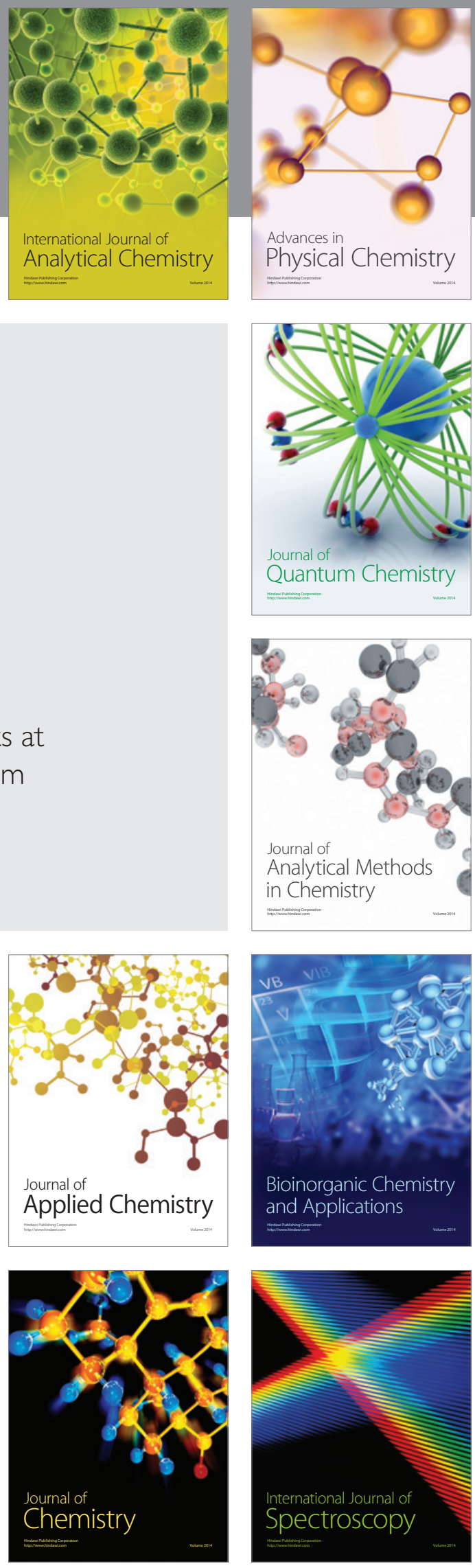